\title{
Effect of cardiac rehabilitation training on patients with coronary heart disease: a systematic review and meta-analysis
}

\author{
Jingjun Li, Yongchun Li, Fengying Gong, Ronglv Huang, Qiang Zhang, Zhaoru Liu, Jintao Lin, Aiwu Li, \\ Ying Lv, Yunshui Cheng
}

Department of Traditional Chinese Medicine, Nanfang Hospital of Southern Medical University, Guangzhou, China

Contributions: (I) Conception and design: J Li, Y Lv, Y Cheng; (II) Administrative support: Y Li, R Huang; (III) Provision of study materials or patients: Q Zhang, Z Liu, F Gong, J Lin, Y Lv, Y Cheng; (IV) Collection and assembly of data: All authors; (V) Data analysis and interpretation: J Li, Y Li, R Huang, Q Zhang; (VI) Manuscript writing: All authors; (VII) Final approval of manuscript: All authors.

Correspondence to: Ying Lv; Yunshui Cheng. Department of Traditional Chinese Medicine, Nanfang Hospital of Southern Medical University, 1838 North Guangzhou Avenue, Guangzhou, China. Email: lvying1966@163.com; Yunshui8000@163.com.

\begin{abstract}
Background: In recent years, the incidence of heart disease has increased and patients are younger. Cardiac rehabilitation training has been proposed to improve the prognosis of patients with heart disease. Cardiac rehabilitation includes moderate-intensity continuous training (MCT) and high-intensity interval training (HIIT). These two training methods have different effects in improving the prognosis of patients. The aim of the present study was to improve reference for patients with cardiac rehabilitation.

Methods: English databases, including PubMed, Cochrane Library, and Embase, were searched from the establishment of the database to April 2021 for randomized controlled trials (RCTs) of rehabilitation training at different intensities. RevMan 5.3 was used for the meta-analysis.

Results: A total of 8 articles (with a total of 465 patients) were included, including 236 patients in the experimental group and 229 patients in the control group. Different intensities of training had statistically significant differences in peak oxygen uptake [mean difference (MD): 1.21, 95\% confidence interval (CI): -0.66 to $3.07, \mathrm{P}=0.20]$ and the left ventricular ejection fraction difference (MD: $2.53,95 \% \mathrm{CI}:-2.10$ to 7.17 , $\mathrm{P}=0.28)$.

Discussion: Cardiac rehabilitation training can effectively improve the patient's cardiac function indicators and self-care ability, and reduce the incidence of cardiovascular disease (CVD). However, large-sample, multicenter, and long-term RCTs are needed to strengthen the findings of the study.
\end{abstract}

Keywords: Cardiac rehabilitation; exercise rehabilitation; meta-analysis; cardiac function; coronary heart disease (CHD)

Submitted Sep 26, 2021. Accepted for publication Nov 16, 2021.

doi: 10.21037/apm-21-3136

View this article at: https://dx.doi.org/10.21037/apm-21-3136

\section{Introduction}

Cardiovascular disease (CVD) is caused by a number of factors, including high blood pressure, smoking, drinking, diabetes, dyslipidemia, and metabolic syndrome. It mainly manifests as ischemic or hemorrhagic diseases in the brain, heart, and body tissue. In 2008, 17.3 million people died of CVD worldwide, accounting for $30 \%$ of total deaths worldwide (1). In 2013, the China Cardiovascular Disease
Report reported that there was an estimated 290 million CVD patients in China, and approximately 3.5 million people die from CVDs every year, and the prevalence and mortality of cardiovascular diseases are still showing an upward trend (2). The incidence of coronary heart disease is affected by many factors. The general incidence rate is about $6 \%$ to $7 \%$, and the mortality rate is about $2 \%$ to $3 \%$ (3). Coronary heart disease (CHD) has the highest mortality and disability rate (4). Cardiac rehabilitation refers 
to the integration of a variety of coordinated and purposeful interventions, such as: rehabilitation assessment, exercise training, diet and behavior, and medical compliance. Cardiac rehabilitation can improve the function and structure of patients with heart disease, optimize their physical and mental strength, and increase their social participation. Cardiac rehabilitation training does not only significantly reduce the prevalence and mortality of CHD but also significantly improve the quality of life of patients. Cardiac rehabilitation training accelerates blood circulation, improves myocardial support capacity, promotes cardiac rehabilitation, and reduces the risk of disability and death. Many studies have confirmed that cardiac rehabilitation is safe and effective (5). However, it has not been fully utilized in clinical work.

Cardiac rehabilitation includes the following three stages: stage I rehabilitation (in-hospital rehabilitation), the patient is required to have no chest pain recurring in the past 8 hours, troponin level has not increased, no new cardiac function decompensation manifestations, no new obvious arrhythmia or dynamic changes of ECG, resting heart rate $50-100$ beats/min, resting blood pressure 90 $150 / 60-100 \mathrm{mmHg}$, blood oxygen saturation $>95 \%$. stage II rehabilitation (early out-of-hospital rehabilitation), and stage III rehabilitation (maintenance period). Stage II and stage III rehabilitation, it is not suitable for patients with unstable angina, uncontrolled disease, abnormal motor system and abnormal metabolism (6). Cardiac rehabilitation exercise can induce adaptive changes in the function and structure of the cardiovascular, respiratory, musculoskeletal, and metabolic systems, and the nature and size of the changes depend on the type, intensity, and duration of the exercise (7). Common training methods include moderateintensity continuous training (MCT) and high-intensity interval training (HIIT). MCT refers to continuous exercise for 20-60 min, with moderate intensity (8); HIIT refers to repeated high-intensity exercise, usually lasting $30 \mathrm{~s}$ to $4 \mathrm{~min}$, and interspersed with recovery time (active/passive, low to medium intensity). Each exercise plus recovery time is 15-45 minutes, 2-5 times a week (9). At present, there are few studies on the effects of MCT and HIIT in improving the exercise capacity and cardiac function of patients.

At present, there are many researches on the evaluation of the effect of cardiac rehabilitation training in the treatment of CVD patients, but there is no systematic evaluation article pointing out the influence of training intensity on the treatment effect of CVD patients. The objective of this meta-analysis was to compare the effects of training methods at different intensities on the rehabilitation of CVD patients. Eight articles were included in the present study, and the research results were reviewed for a scientific basis and theoretical reference for choosing an appropriate intensity of cardiac rehabilitation training in clinical work. We present the following article in accordance with the PRISMA reporting checklist (available at https://dx.doi.org/10.21037/apm-21-3136).

\section{Methods}

\section{Literature retrieval}

PubMed, Cochrane Library, and Embase were searched using the following terms: "cardiac rehabilitation", "coronary heart disease", "cardiovascular rehabilitation", "coronary atherosclerotic heart disease", and "treatment effect", combined with the following descriptive terms: "ejection fraction", "self-care ability", and "length of hospital stay". The search time was from the establishment of the database until April 2021. Literature was identified following the pre-established inclusion and exclusion criteria.

\section{Literature inclusion and exclusion criteria}

The inclusion criteria were as follows: (I) randomized controlled trials (RCTs) of cardiac rehabilitation training, regardless of whether allocation concealment or blinding was used; (II) patients aged 30-79 years old and diagnosed with CHD; (III) intervention measures for the experimental group were HIIT (the intensity was more than $76 \%$ of the maximum heart rate or $65 \%$ of the maximum oxygen uptake) and MCT (the intensity was $64-75 \%$ of maximum heart rate or $46-64 \%$ of maximum oxygen uptake); and (IV) measurement indicators were peak oxygen uptake, left ventricular ejection volume, left ventricular end-diastolic volume, 6-min walk test, quality of life assessment scale, and low-density lipoprotein.

The exclusion criteria were as follows: (I) the original text was not obtained; (II) articles in Chinese; (III) statistical data could not be extracted; (IV) articles with insufficient information; (V) documents with unreliable results; and (VI) non-RCTs.

\section{Data extraction}

The data extraction was carried out independently by 
two researchers, and any inconsistencies were resolved by discussions or by consulting a third researcher. The data to be extracted for this study included basic article information (title, first author, publication year, author information, document source), basic characteristics of study participants (sex, age, research sample size, baseline comparability), literature research methods, research plan design, intervention measures for experimental group and control group, and outcome evaluation indicators.

\section{Quality assessment}

The quality evaluation was carried out as per the risk of bias assessment recommended by the Cochrane Handbook for Systematic Reviews of Interventions (version 5.3). The evaluation content includes the following 7 items: (I) which random method to use; (II) whether to perform allocation concealment; (III) the implementation of blinding between patients and investigators; (IV) the effect of blinding; (V) whether the results were complete; (VI) whether the survey results were credible; and (VII) other biases. For each RCT, "satisfied" meant small bias, and "unsatisfied" meant high bias. Each item scored 1 point, and a total score between 1 and 3 was considered low quality; a total score between 4 and 7 was considered high quality.

\section{Data analysis}

Forest map clearly shows the results of each study. No overlap between the confidence intervals (CIs) of the results of each study indicated no statistical homogeneity between the studies.

\section{Sensitivity analysis}

The sensitivity analysis investigated whether a single study affected the overall results of the combination, which would have an impact on comprehensive research in the following two situations. First, when a study is deleted, the result will be significantly different. If there is little difference in the overall results when a study is deleted, it indicates the sensitivity of the combined results and the results obtained are unstable. Second, the results show sensitivity and stability, and the conclusion is correct.

\section{Statistical analysis}

RevMan5.3 software by the Cochrane Collaboration was used for the meta-analysis. The odds ratio (OR) was used as the effect size, and the $95 \%$ CI expressed the result. The included studies were first tested for heterogeneity, with $\alpha=0.1$ as the test level. If there was no heterogeneity between the studies ( $\left.\mathrm{P}>0.1, \mathrm{I}^{2}<50 \%\right)$, the fixed-effects model (FEM) was selected for the meta-analysis; if there was heterogeneity between studies $\left(\mathrm{I}^{2}>50 \%\right)$, the random-effects model (REM) was selected for the meta-analysis. $\mathrm{P}<0.05$ indicated that the difference was statistically significant. When a single risk factor analysis was included in more than 10 articles, a funnel chart was used to analyze the publication bias of each risk factor.

\section{Results}

\section{Literature retrieval results}

Of the 833 articles initially identified, 562 were retrieved from database, 271 were from registers. Then, 586 duplicate articles were removed, and 186 that did not meet the inclusion criteria were further excluded after reading the title and the abstract; 53 articles were excluded after reading the full text, and finally, 8 articles that met the inclusion criteria were included (10-17). The retrieval process is shown in Figure 1, and the basic information of the included literature is shown in Table 1.

\section{Risk of bias assessment results}

Cochrane Handbook for Systematic Reviews of Interventions version 5.3 was used to evaluate the risk of bias of the 8 articles included in the present study. The risk of bias was charted, as shown in Figures 2,3, and expressed using RevMan 5.3 software.

\section{Peak oxygen uptake}

Eight articles were included in the present study and reported the peak cardiac oxygen uptake of patients after training at different intensities. A total of 236 patients in the experimental group were measured for peak oxygen uptake, while 229 patients in the control group were measured. After heterogeneity testing, the results showed that $\mathrm{I}^{2}=71 \%$ and $\mathrm{P}=0.001$, which indicated that the literature had obvious heterogeneity. The REM was then used for analysis. The meta-analysis results showed that MD: $1.21,95 \%$ CI: -0.66 to $3.07, Z=1.27$, and $\mathrm{P}=0.20$. Therefore, there was no significant difference in peak oxygen uptake between the 


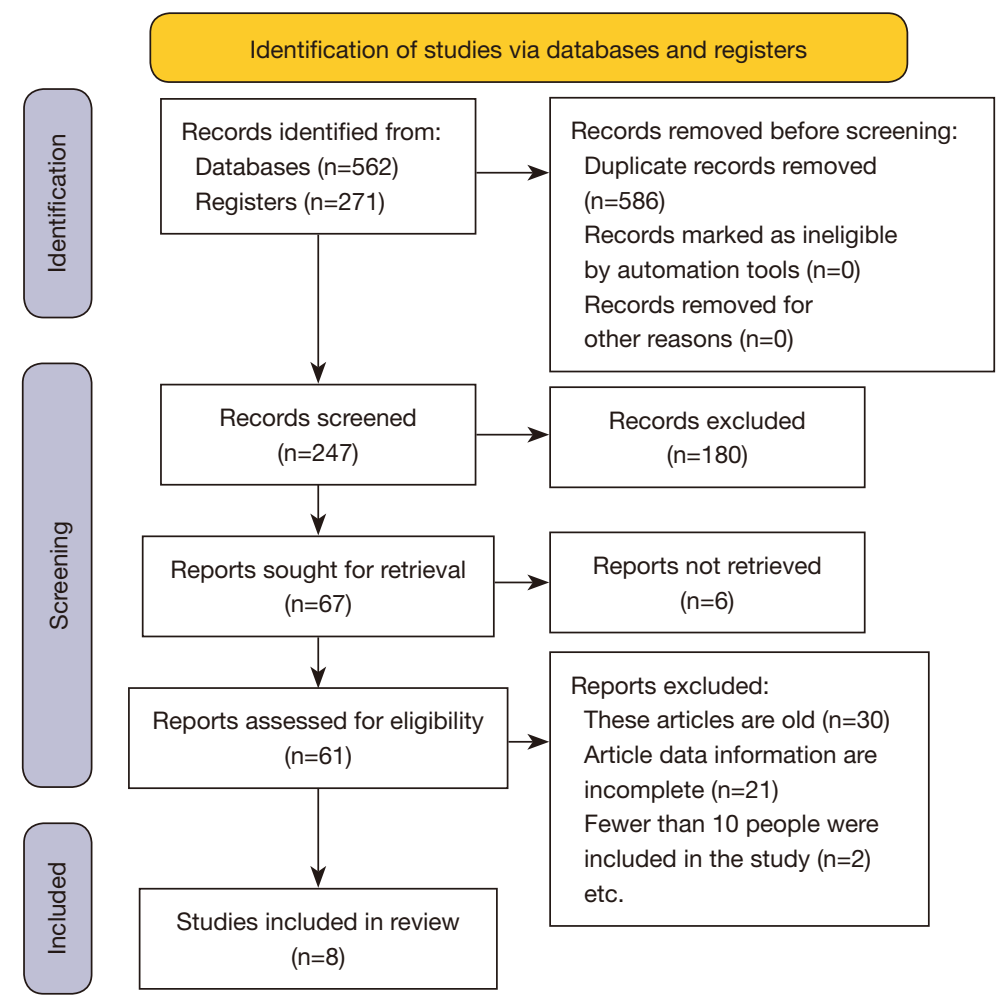

Figure 1 Literature retrieval process.

two groups of patients after training at different intensities $(\mathrm{P}>0.05)$. The forest plot is shown in Figure 4.

As shown in Figure 5, the funnel chart was symmetrical, and most of the data corresponded to points within the $95 \%$ $\mathrm{CI}$, indicating that that publication bias was effective so that the results related to the peak oxygen uptake of patients at different training intensities were above $5 \mathrm{k}+10=95$.

\section{Left ventricular ejection fraction}

Five articles included in the present study reported the left ventricular ejection fraction of patients after different intensities of training. Left ventricular ejection fraction was measured in 236 patients in the experimental group and 229 patients in the control group. The heterogeneity test showed that $\mathrm{I}^{2}=95 \%$ and $\mathrm{P}<0.00001$, which indicated that there was obvious heterogeneity in the literature. The REM was then used for analysis. The meta-analysis results showed that MD: $2.53,95 \% \mathrm{CI}:-2.10$ to $7.17, \mathrm{Z}=1.07$, and $\mathrm{P}=0.28$. Therefore, there was no significant difference in left ventricular ejection fraction between the two groups of patients after training at different intensities $(\mathrm{P}>0.05)$. The forest plot is shown in Figure 6.
As shown in Figure 7, the funnel chart was symmetrical, and most of the data corresponded to points within the $95 \%$ CI, indicating that the publication bias was effective so that the results of left ventricular ejection fraction of patients at different training intensities were above $5 \mathrm{k}+10=95$.

\section{Left ventricular end-diastolic volume}

Four articles included in the present study reported the left ventricular end-diastolic volume of patients after different intensities of training. The left ventricular enddiastolic volume was measured in 153 patients in the experimental group and 137 patients in the control group. The heterogeneity test showed that $\mathrm{I}^{2}=76 \%$ and $\mathrm{P}=0.005$, which indicated that there was obvious heterogeneity in the literature. The REM was then used for analysis. The meta-analysis results showed that MD: $-3.68,95 \% \mathrm{CI}$ : -13.52 to $6.15, \mathrm{Z}=0.73$, and $\mathrm{P}=0.46$. Therefore, there were significant differences in the left ventricular end-diastolic volume between the two groups of patients after training at no different intensities $(\mathrm{P}>0.05)$. The forest plot is shown in Figure 8.

As shown in Figure 9, the funnel chart was symmetrical, 
Table 1 Basic information of the included literature

\begin{tabular}{|c|c|c|c|c|c|c|}
\hline $\begin{array}{l}\text { Wisløff et al. } \\
\text { (10) }\end{array}$ & 2007 & 9 & 9 & $\begin{array}{l}\text { Peak oxygen uptake, left ventricular } \\
\text { ejection fraction, left ventricular end- } \\
\text { diastolic volume }\end{array}$ & $\begin{array}{l}58 \text { years } \\
\text { (average) }\end{array}$ & $\begin{array}{l}\text { Heart failure patients after } \\
\text { myocardial infarction }\end{array}$ \\
\hline $\begin{array}{l}\text { Ellingsen } \\
\text { et al. (11) }\end{array}$ & 2017 & 77 & 65 & $\begin{array}{l}\text { Peak oxygen uptake, left ventricular } \\
\text { ejection fraction }\end{array}$ & 58-68 years & $\begin{array}{l}\text { Patients with heart failure and } \\
\text { decreased ejection fraction }\end{array}$ \\
\hline $\begin{array}{l}\text { Villelabeitia- } \\
\text { Jaureguizar } \\
\text { et al. (12) }\end{array}$ & 2019 & 57 & 53 & $\begin{array}{l}\text { Peak oxygen uptake, 6-min walking } \\
\text { test, quality of life evaluation scale }\end{array}$ & $\begin{array}{l}58 \text { years } \\
\text { (average) }\end{array}$ & $\mathrm{CHD}$ \\
\hline $\begin{array}{l}\text { Jaureguizar } \\
\text { et al. (13) }\end{array}$ & 2016 & 36 & 36 & Peak oxygen uptake & $\begin{array}{l}58 \text { years } \\
\text { (average) }\end{array}$ & CHD patients \\
\hline $\begin{array}{l}\text { Benda et al. } \\
\text { (15) }\end{array}$ & 2015 & 10 & 10 & $\begin{array}{l}\text { Peak oxygen uptake, left ventricular } \\
\text { ejection fraction, left ventricular } \\
\text { end-diastolic volume, quality of life } \\
\text { evaluation form }\end{array}$ & $\begin{array}{l}63.5 \text { years } \\
\text { (average) }\end{array}$ & $\begin{array}{l}\text { Patients with heart failure and } \\
\text { decreased ejection fraction }\end{array}$ \\
\hline $\begin{array}{l}\text { Novaković } \\
\text { et al. (16) }\end{array}$ & 2018 & 9 & 9 & $\begin{array}{l}\text { Peak oxygen uptake, left ventricular } \\
\text { ejection fraction, left ventricular } \\
\text { end-diastolic volume, quality of } \\
\text { life evaluation form, low-density } \\
\text { lipoprotein, high-density lipoprotein }\end{array}$ & $\begin{array}{l}38 \text { years } \\
\text { (average) }\end{array}$ & $\begin{array}{l}\text { Adult patients who had } \\
\text { tetralogy of Fallot in childhood }\end{array}$ \\
\hline
\end{tabular}

$\mathrm{CHD}$, coronary heart disease.

and most of the data corresponded to points within the $95 \%$ CI, indicating that the publication bias was effective so that the results of left ventricular end-diastolic volume of patients at different training intensities were above $5 \mathrm{k}+10=95$.

\section{Discussion}

Eight articles were included in this meta-analysis (10-17). Of these, 6 reported age, follow-up time, and observation indicators between the experimental group and the control group, and there was no statistically significant difference $(\mathrm{P}>0.05)$. All 8 articles used random grouping to divide the patients into the experimental group and control group, but none reported the blinding method and the blood loss during the observation process. The sample size of the literature included in the present study was small, and there may be bias in the measurement of some indicators. To improve the reliability of the research, an expanded sample size is needed in the future. As the incidence of heart disease increases in middle-aged and elderly people, CVD has become the main cause of death (18). Cardiac rehabilitation training can significantly improve cardiac function. First, cardiac rehabilitation training can improve the function of endothelial progenitor cells and the structure of coronary arteries, expand the coronary arteries, and establish collateral circulation, thereby increasing blood flow and myocardial support (19). Second, it can regulate vascular tension, improve arterial compliance, and lower the patient's blood pressure at rest (20). Finally, it can control mood swings, improve negative emotions, maintain the body's energy balance, and reduce fat accumulation (21). Literature has reported that cardiac rehabilitation training does not only greatly reduce the prevalence and mortality of 


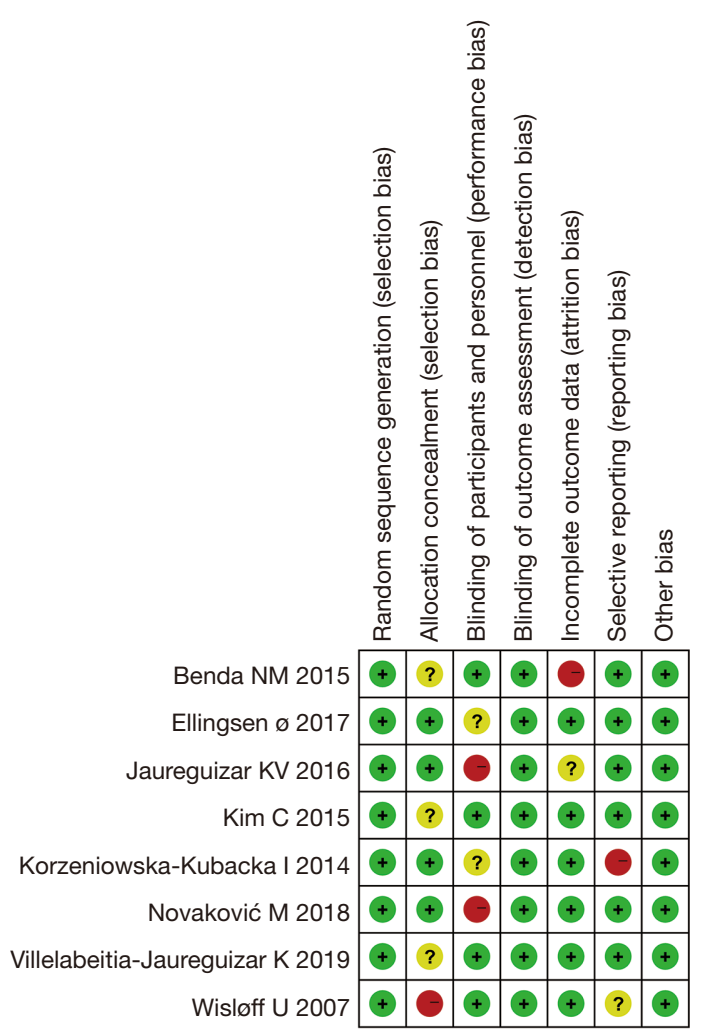

Figure 2 Risk of bias assessment of included literature.
CHD, but also significantly improves the quality of life of patients (5).

Through the meta-analysis of the original data of the 8 studies, we found that HIIT can improve the patient's cardiac function and prognosis. For example, it can increase the patient's peak oxygen uptake and elevate the left ventricular oxygen uptake fraction and end-diastolic volume of the left ventricle. In the 6-min walk experiment, the overall performance of patients who did HIIT was better than that of patients who did MCT. Because the follow-up time of each study was inconsistent and short, it is impossible to make an accurate analysis of the long-term quality of life of patients. At present, there are relatively few reports on the prognosis of cardiac rehabilitation training. The main reason is that the compliance of cardiac rehabilitation training is poor and must be performed under the discretion of researchers. The information collected in this study may have publication bias, which affects the reliability of the meta-analysis. HIIT is helpful for the recovery and prognosis of patients with heart diseases. However, due to the inability to obtain sufficient evidence, high-quality, large-sample, and multicenter RCTs are needed to study the effects of HIIT and MCT on the rehabilitation of patients with heart disease.

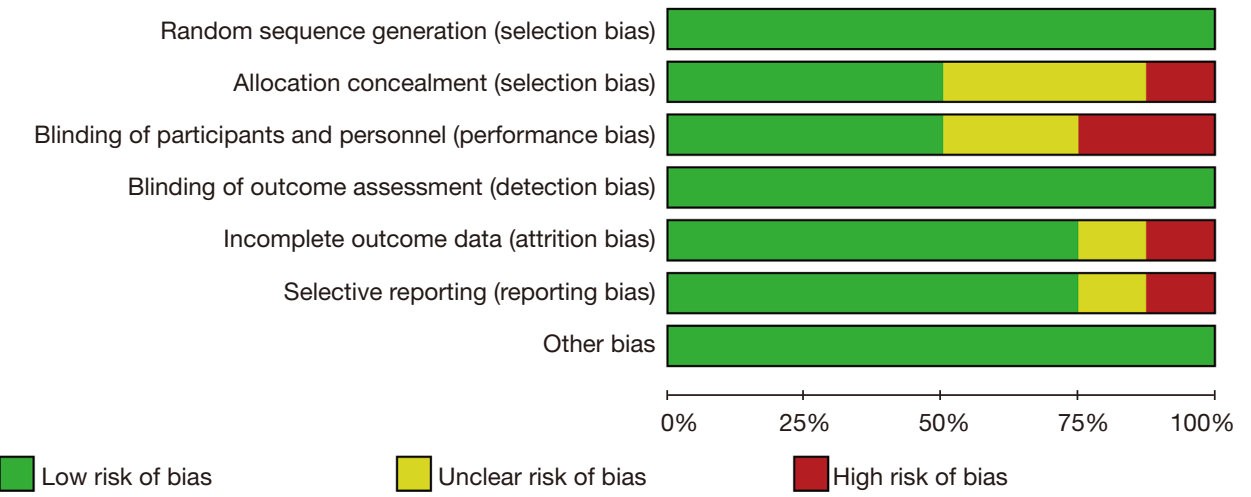

Figure 3 Risk of bias assessment of included literature. 


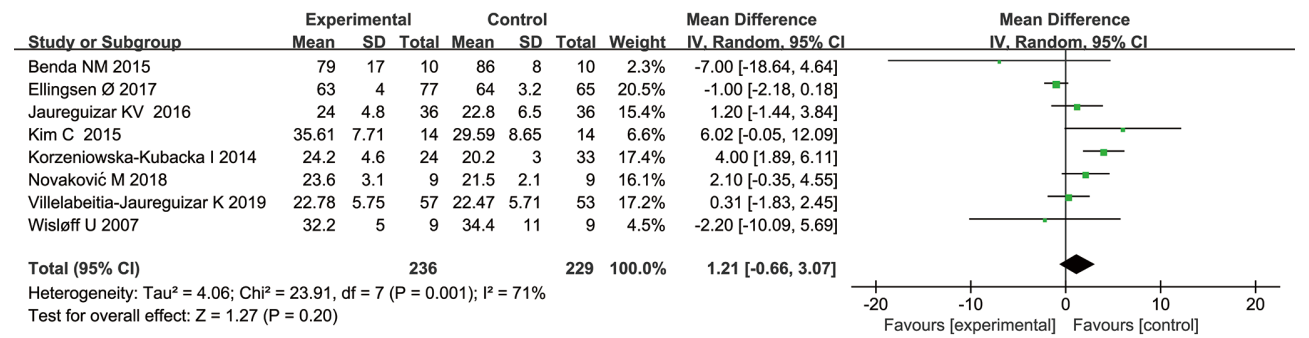

Figure 4 Forest plot of peak oxygen uptake for the two groups of patients. CI, confidence interval; SD, standard deviation.

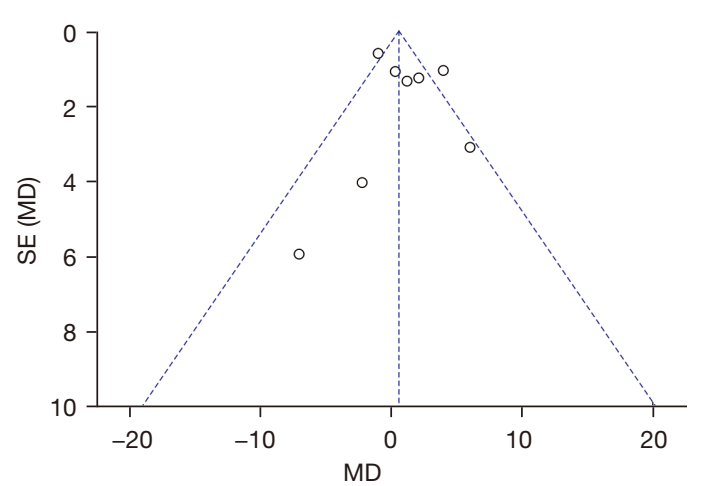

Figure 5 Funnel chart of peak oxygen uptake of the two groups of patients. MD, mean different; SE, standard error.

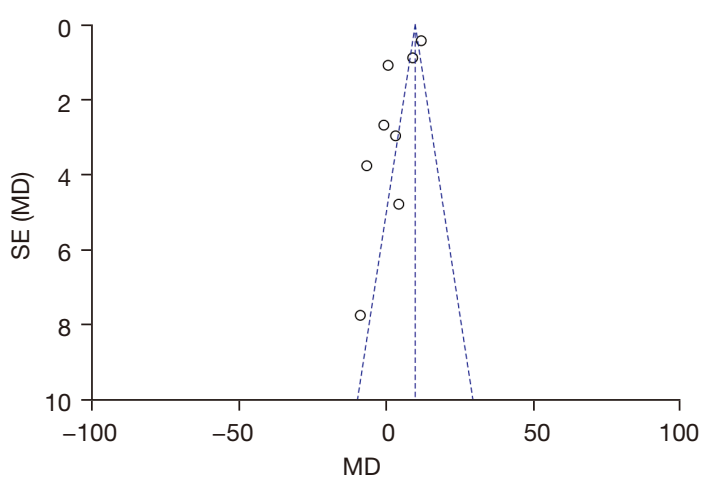

Figure 7 Funnel chart of left ventricular ejection fraction of two groups of patients. MD, mean different; SE, standard error.

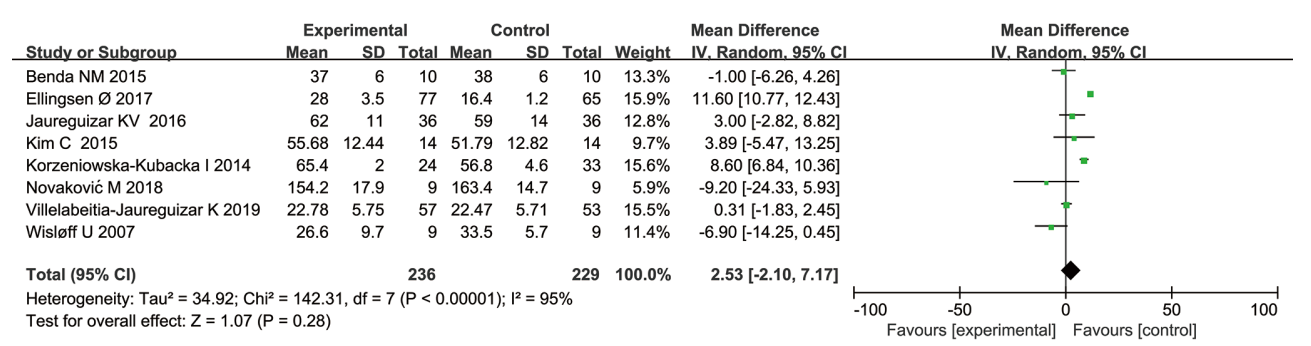

Figure 6 Forest plot of left ventricular ejection fraction of the two groups of patients.

\section{Conclusions}

In this study, 8 articles were included in the meta-analysis. It was found that there was a significant difference in peak oxygen uptake, left ventricular ejection fraction, the left ventricular end-diastolic volume, the results of the 6-min walk experiment, quality of life, and low-density lipoprotein between the two groups of patients after training at different intensities $(\mathrm{P}<0.05)$. Cardiac rehabilitation training does not only improve cardiac function, peak oxygen uptake, left ventricular ejection fraction, and left ventricular end-diastolic volume of patients with heart disease, but also reduces the incidence of CVD and extends the distance of 6-min walking experiment, which should be promoted in the clinical setting. 


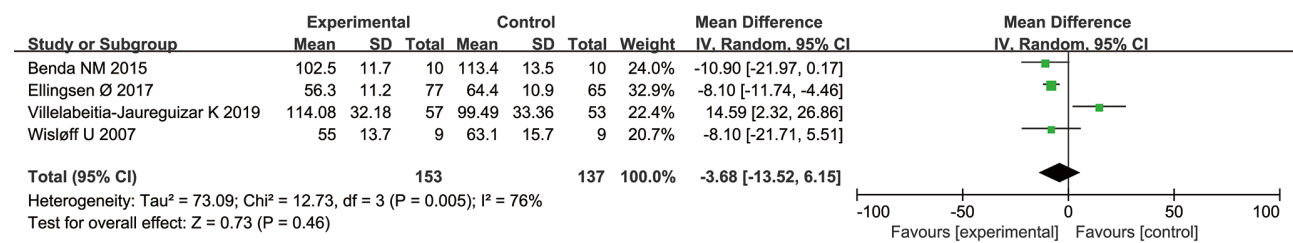

Figure 8 Forest plot of the left ventricular end-diastolic volume of the two groups of patients. CI, confidence interval; SD, standard deviation.

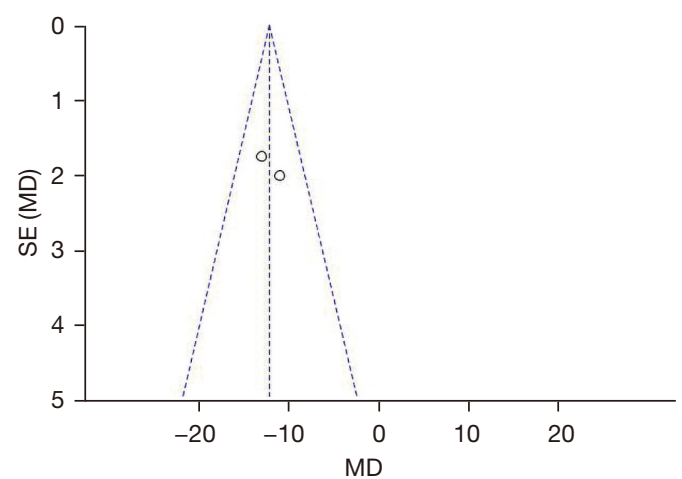

Figure 9 Funnel chart of left ventricular end-diastolic volume. $\mathrm{MD}$, mean different; SE, standard error.

\section{Acknowledgments}

Funding: None.

\section{Footnote}

Reporting Checklist: The authors have completed the PRISMA reporting checklist. Available at https://dx.doi. org/10.21037/apm-21-3136

Conflicts of Interest: All authors have completed the ICMJE uniform disclosure form (available at https://dx.doi. org/10.21037/apm-21-3136). The authors have no conflicts of interest to declare.

Ethical Statement: The authors are accountable for all aspects of the work in ensuring that questions related to the accuracy or integrity of any part of the work are appropriately investigated and resolved.

Open Access Statement: This is an Open Access article distributed in accordance with the Creative Commons Attribution-NonCommercial-NoDerivs 4.0 International License (CC BY-NC-ND 4.0), which permits the non- commercial replication and distribution of the article with the strict proviso that no changes or edits are made and the original work is properly cited (including links to both the formal publication through the relevant DOI and the license). See: https://creativecommons.org/licenses/by-nc-nd/4.0/.

\section{References}

1. Kasargod Prabhakar CR, Stewart R. Physical activity and mortality in patients with stable coronary heart disease. Curr Opin Cardiol 2018;33:653-9.

2. Chen G, Levy D. Contributions of the Framingham Heart Study to the Epidemiology of Coronary Heart Disease. JAMA Cardiol 2016;1:825-30.

3. Cybulska B, Kłosiewicz-Latoszek L. Landmark studies in coronary heart disease epidemiology. The Framingham Heart Study after 70 years and the Seven Countries Study after 60 years. Kardiol Pol 2019;77:173-80.

4. Wirtz PH, von Känel R. Psychological Stress, Inflammation, and Coronary Heart Disease. Curr Cardiol Rep 2017;19:111.

5. de Gregorio C. Physical Training and Cardiac Rehabilitation in Heart Failure Patients. Adv Exp Med Biol 2018;1067:161-81.

6. Khadanga S, Savage PD, Ades PA. Resistance Training for Older Adults in Cardiac Rehabilitation. Clin Geriatr Med 2019;35:459-68.

7. Giallauria F, Piccioli L, Vitale G, et al. Exercise training in patients with chronic heart failure: A new challenge for Cardiac Rehabilitation Community. Monaldi Arch Chest Dis 2018;88:987.

8. Kachur S, Lavie CJ, Morera R, et al. Exercise training and cardiac rehabilitation in cardiovascular disease. Expert Rev Cardiovasc Ther 2019;17:585-96.

9. Long L, Mordi IR, Bridges C, et al. Exercise-based cardiac rehabilitation for adults with heart failure. Cochrane Database Syst Rev 2019;1:CD003331.

10. Wisløff U, Støylen A, Loennechen JP, et al. Superior 
cardiovascular effect of aerobic interval training versus moderate continuous training in heart failure patients: a randomized study. Circulation 2007;115:3086-94.

11. Ellingsen $\varnothing$, Halle M, Conraads V, et al. High-Intensity Interval Training in Patients With Heart Failure With Reduced Ejection Fraction. Circulation 2017;135:839-49.

12. Villelabeitia-Jaureguizar K, Vicente-Campos D, Berenguel Senen A, et al. Mechanical efficiency of high versus moderate intensity aerobic exercise in coronary heart disease patients: A randomized clinical trial. Cardiol J 2019;26:130-7.

13. Jaureguizar KV, Vicente-Campos D, Bautista LR, et al. Effect of High-Intensity Interval Versus Continuous Exercise Training on Functional Capacity and Quality of Life in Patients With Coronary Artery Disease: A RANDOMIZED CLINICAL TRIAL. J Cardiopulm Rehabil Prev 2016;36:96-105.

14. Kim C, Choi HE, Lim MH. Effect of High Interval Training in Acute Myocardial Infarction Patients with Drug-Eluting Stent. Am J Phys Med Rehabil 2015;94:879-86.

15. Benda NM, Seeger JP, Stevens GG, et al. Effects of High-Intensity Interval Training versus Continuous Training on Physical Fitness, Cardiovascular Function and Quality of Life in Heart Failure Patients. PLoS One 2015;10:e0141256.

16. Novaković M, Prokšelj K, Rajkovič U, et al. Exercise training in adults with repaired tetralogy of Fallot: A

Cite this article as: Li J, Li Y, Gong F, Huang R, Zhang Q, Liu Z, Lin J, Li A, Lv Y, Cheng Y. Effect of cardiac rehabilitation training on patients with coronary heart disease: a systematic review and meta-analysis. Ann Palliat Med 2021;10(11):11901-11909. doi: 10.21037/apm-21-3136 randomized controlled pilot study of continuous versus interval training. Int J Cardiol 2018;255:37-44.

17. Korzeniowska-Kubacka I, Bilińska M, DobraszkiewiczWasilewska B, et al. Comparison between hybrid and standard centre-based cardiac rehabilitation in female patients after myocardial infarction: a pilot study. Kardiol Pol 2014;72:269-74.

18. Lutz AH, Delligatti A, Allsup K, et al. Cardiac Rehabilitation Is Associated With Improved Physical Function in Frail Older Adults With Cardiovascular Disease. J Cardiopulm Rehabil Prev 2020;40:310-8.

19. Vasheghani-Farahani A, Asef-Kabiri L, Masoudkabir F, et al. Effect of exercise-based cardiac rehabilitation following coronary artery bypass surgery on ventricular repolarization indices. J Cardiopulm Rehabil Prev 2011;31:239-44.

20. Manzoni GM, Villa V, Compare A, et al. Short-term effects of a multi-disciplinary cardiac rehabilitation programme on psychological well-being, exercise capacity and weight in a sample of obese in-patients with coronary heart disease: a practice-level study. Psychol Health Med 2011;16:178-89.

21. Sibilitz KL, Berg SK, Rasmussen TB, et al. Cardiac rehabilitation increases physical capacity but not mental health after heart valve surgery: a randomised clinical trial. Heart 2016;102:1995-2003.

(English Language Editor: R. Scott) 